Textures and Microstructures, 1991, Vols 14-18, pp. 115-120 Reprints available from the publisher

Photocopying permitted by license only
(C) 1991 Gordon and Breach Science Publishers SA Printed in the United Kingdom

\title{
X-RAY MEASUREMENT OF RESIDUAL AUSTENITE IN TEXTURED STEEL SPECIMEN
}

\section{TAKUJI SHINDOH and SHIN-ICHI NAGASHIMA}

$R \& D$ Laboratories-II, R \& D Bureau, Nippon Steel Corporation

20-1 Shintomi, Futtsu, Chiba-ken, 299-12 JAPAN

\section{INTRODUCTION}

The method of $x$-ray measurement of volume fraction of residual austenite in steels has been investigated for a powdered specimen as well as randomly oriented sheet specmen ${ }^{1-6)}$. The volume fraction of austenite, $V_{\gamma}$, is determined by the following equations :

$$
V_{\gamma}=\left(R_{\alpha} / R_{\gamma}\right) I_{\gamma} /\left(I_{\alpha}+\left(R_{\alpha} / R_{\gamma}\right) I_{\gamma}\right)
$$

where $I_{\gamma}$ and $I_{\alpha}$ are the intensity of diffraction lines of austsenite and martensite phases, respectivesly, $R_{\gamma}$ and $R_{\alpha}$ factors are given empirically or theoretically for various kinds of combination of diffraction lines of both phases.

In the case of textured specimen, however, it is necessary to take the preferred orientation of the austenite and the martensite phases into account. Morris tried to make a correction of diffraction intensities through the measurement of the pole figures of both phases ${ }^{6}$ ).

As there are number of studies on the transformation texture, orientation relationship and the variant selection due to the stress state ${ }^{10-18)}$, it is possible to estimate the transformation textures of martensite if the initial texture of austenite and the stress state during transformation is given.

In the present paper, the authors have tried to make clear the effect of transformation textures of the martensite on the determination of volume fraction of the residual austenite by the use of equation (1).

SPECIMEN AND EXPERIMENTAL METHODS

Specimen Commercial austenitic stainless steel sheet, 
Table 1. Chemical Composition of the Steel

\begin{tabular}{lcccccccc}
\hline Steel & $\mathrm{C}$ & $\mathrm{Si}$ & $\mathrm{Mn}$ & $\mathrm{Ni}$ & $\mathrm{Cr}$ & $\mathrm{Cu}$ & $\mathrm{N}$ & $\mathrm{Fe}$ \\
\hline Sus301 & .01 & .62 & .99 & 7.52 & 17.56 & - & .02 & $\mathrm{Bal}$ \\
\hline
\end{tabular}

was used for the test specimen. The chemical composition of the specimen is shown in Table 1.

Texture measurement For the texture measurement of austenite phase the cold rolled and annealed sheet was used, and for the martensite phase, the specimen was taken from the elongated and fractured test piece. The tensile test was carried out with the strain rate of $0.167 / \mathrm{sec}$ at $77 \mathrm{~K}$. It was confirmed that the region near the fractured edge was all transformed into martensite.

Pole figures were measured by the Schulz refcection method using $C_{0} \mathrm{~K} \alpha$ radiation. And three dimensional analysis was carried out by the use of Vector method ${ }^{8}, 91$ from the (111) pole figure of austenite phase and the (110) pole figutre of martensite phase.

\section{SIMULATION OF TRANSFORMATION TEXTURES}

Caluculation of Transformation Texture For the simulation of the transformation textures the program developed by Furubayashi was used, and the following stress criteria were appplied ${ }^{10}$ l.

(1) Rolling stress criterion (RSC): Combination of the simple compressive stress along the sheet normal direction (ND) and the simple tensile stress along the rolling directin (RD). The ratio of compressive and tensile stresses,

(2) Anti-rolling stress (ARS) : Stress is reverse direction as the RSC, i.e., the combinatiaon of compressive stress along $\mathrm{RD}$ and the tensile stress along ND.

(3) Pure tension stress (PTS): In this stress mode, the tensile stress along certain direction is unity but the stresses along other directions are zero.

(4) Plane strain tensile stress (PST): In this case, tensile stresses are applied along the minor principal axis is half value of the one of the major principal axis.

The variant selection is determined as follows:

(1) Active slip system model ${ }^{10,12,13)}$ : It is assumed that the resolved shear stress concerned with each slip system is proprtional to the Tucker factor, TF. In the "Strong Selection", the slip system that has the largest $\mathrm{TF}$ is selected as the active slip system. In the "Weak selection", active slip system is determined by Monte-Carlo method from all the slip systems that have the TF larger than the maximum work factor, MWF, which is given as one of the boundary 
condztion.

(2) Twinning shear model10,141:

When Nishiyama's relationship is applied for transformation, the variant selection due to twinning shear model can be easily treated.

(3) Lattice distorsion model 10,15): By the use of Bain's distorsion mechanism, the variant selection due to this model can be easily calculated.

RESULTS

Texture of Austenite and Martensite Phases The measured (111) pole figure of austenite is shown in Fig.1(a). By means of Vector method analysis, it was clarified that the major texture components are (235)[111], (112)[111], (368) $[656],(166)[665]$. The recalculated (111) pole figure is shown in Fig.l(b), which is well agreed with Fig.l(a).

The (110) pole figure of martensite phase was measured and is shown in Fig. 2(a). Transformation texture was calculatead under pure tensile stress models (PTS) along RD TD and ND, and only the PTS model along ND well agreed with the observed result, as shown in Fig. $2(\mathrm{~b})$.

Intensity of Diffraction Lines of Martensite It is clear that the intensitiy of each diffraction lines varies due to preferred orientation even if the volume fraction of the martensite phase. As the calculation of equation (1) the intensity of austenite and martensite was measured by the various kinds of combinatoin, such as $220+311+222,220$ $+311,200+220$ or 220 for austenite and $200+211+220,200+220$ $200+211$ for martensite $4,5,71$. The intensity of pole density if $100,110,111$ and 211 of martensite was detemined from the ND inverse pole figure and was given in Table 2. The examples of ND inverse pole figure is shown in Fig. 3.

Change in Austenite Volume Fraction Due to Texture The change in calculated austenite volume fraction was compared with the observed and calculated textures. The models such as pure tensile stress along ND, tensile stress along ND with compressive stress along $\mathrm{RD}$. The result is shown in Table 3 .

\section{DISCUSSION AND CONCLUSION}

Simulation of Transformation Texture In the present study, the authors further calculated under various types of stress state, such as (1) RSC, tension along RD and compression along ND, (2) ARS, tension along ND and Compression along $\mathrm{RD}$; (3) $\mathrm{PST}, \mathrm{RD}(1)-\mathrm{ND}(0.5)$, i.e., tensile stress along RD(unity) and tensile stress along ND(0.5); (4) PST, ND(1)-RD(0.5), the reversed stress state as the case (3); and (5) PST, ND(1)-TD(0.5). Among these stress 
Table 2. Pole Intensity* of Major Lattice Plane

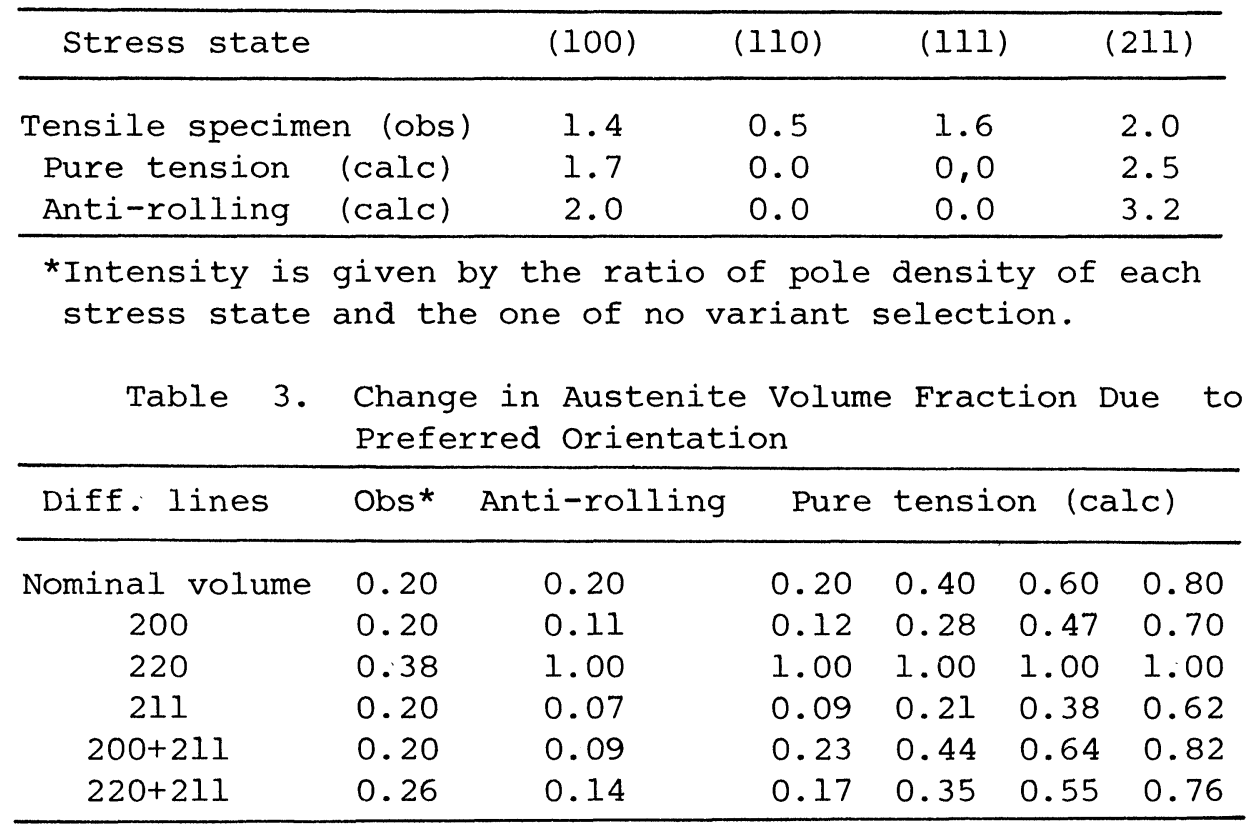

*Obs: Calculated from the ODF of martensite in the deformed specimen

models, (2) and (4) showed very good agrement and

gave nearly the same result as the observed ones.

These results agree with Furubayashi's calculation, who confirmed that the transformation after cold rolling of austenitic stainless steel agrees with the simulation under anti-rolling stress state ${ }^{10}$ ).

Calculation of Austenite Volume Fraction by $\mathrm{x}$-Rays As Morris stated ${ }^{6}$ ), in order to estimate the exact volume fraction of residual austsenite in textured specimen, it is necesary to measure the texture of both austenite and martensite phases, and the diffractaion intensity should be corrected.

\section{ACKNOWLEDGEMENT}

The authors would like to express their appreciation to Professors Baro amd Ruer who provided full program of the vector method. The authors wish to thank to Mr. Nishikawa for his effort to carry out the experiment and the analysis of textures, and they are grateful to Dr. H. Abo for his continuing encouragemant and helpful suggestions. 


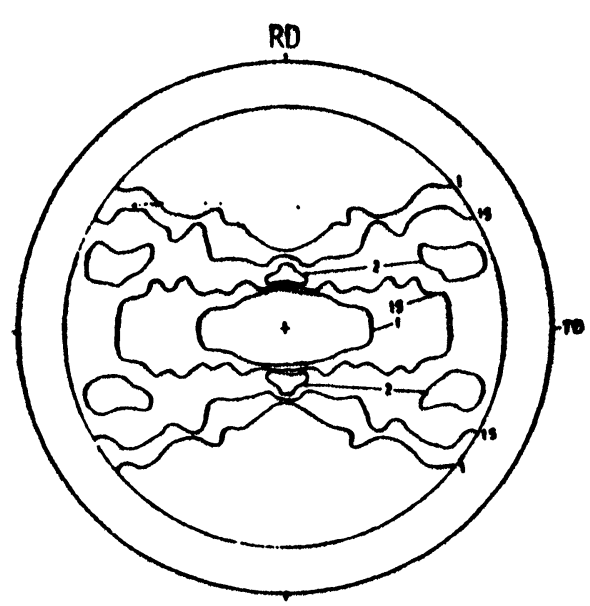

(111)

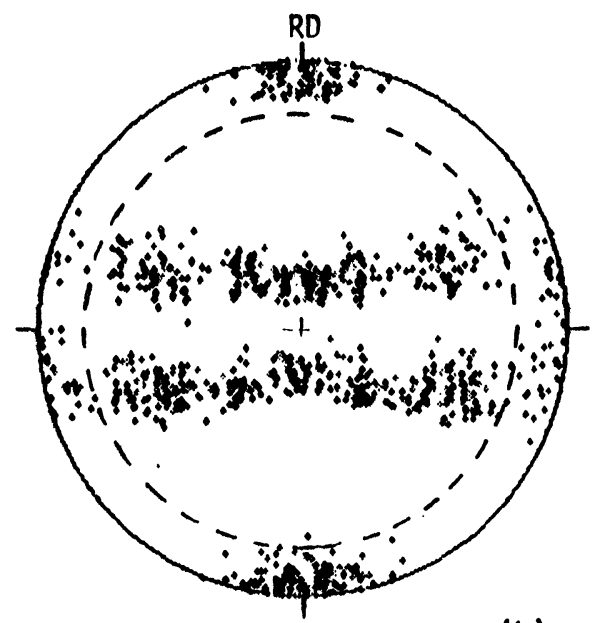

(111)

(b)

Fig. 1. (111) Pole figure of initial austenite phase. (a) Measured, (b) recalculated from ODF.
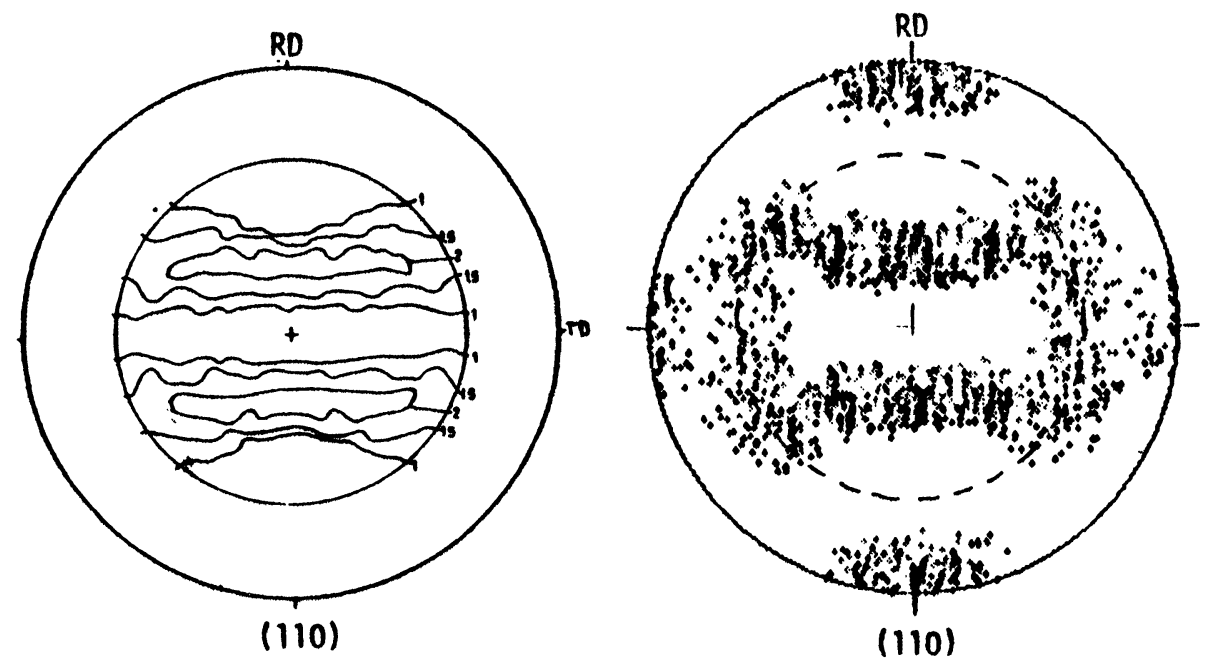

Fig. 2. (110) Pole figure of martensite phase.

(a) Measured, (b) calculated from ODF of $\gamma$. 

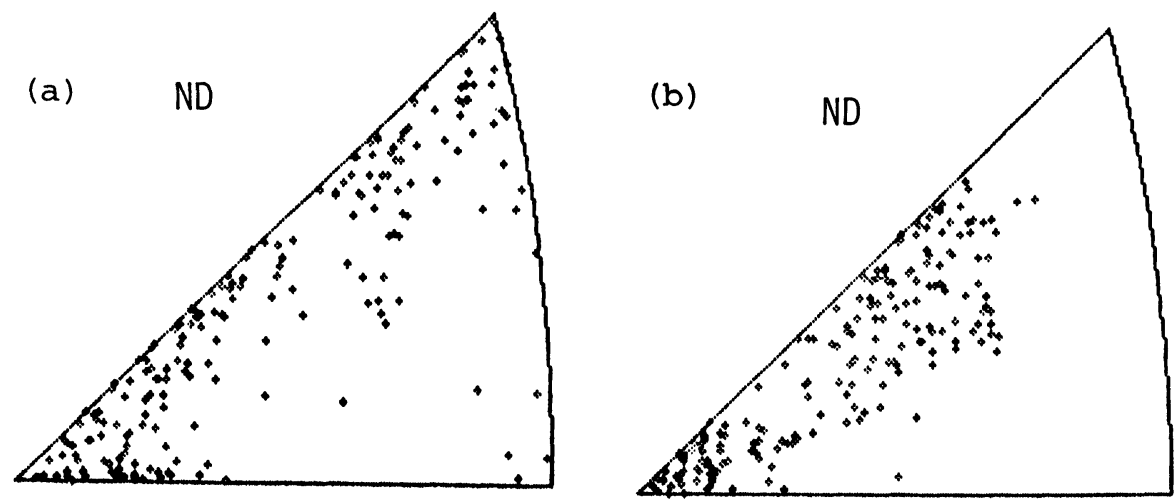

Fig. 3. ND pole figures of martensite phase.

(a) Measured, (b) calculated from ODF of $\gamma$.

\section{REFERENCES}

1. S. Sekito, Sci. Rept. Tohoku Imp. Univ, 20 (1931), 369-376.

2. B. L. Averbach and M. Cohen,Trans. AIME, ,176 (1948),401418.

3. B. L. Averbach, L. S. Castleman and M. Cohen, Trans.ASM. $42(1950), 112-120$.

4. K. E. Beu, Trans. ASM, ,14(1952),1327-1928; ibid.195(1953) 1539-1540.

5. R. L. Miller, Trans. ASM, ,57(1964),892-899.

6. P. Morris, Trans. Met.Soc. AIME, , 239 (1967), 1586-1590.

7. B. D. Culity, Elements of X-Ray Diffraction (AddsisonWesley Publ. Co. Inc. 1978), 379.

8. D. Ruer and R.Baro, Advance in X-Ray Analysis, , 20 (1977), 187.

9. D. Ruer, A. Vadon and R. Baro, Texture of Cryst. Solids, 3 (1979), 249.

10. E. Furubayashi, Tetsu-to-Hagané,71 (1985),1155-1162;ibid, 71 (1985),1359-1366; Metals, Agné (Tokyo,Japan ),April, 28-35; Trans. ISIJ., 27 (1987), 513.

11. F.Borik and R.H.Richman, TMS.AIME.,239(1967),675.

12. H. Abe and K. Itoh, J.J.I.M., 31 (1957), 1300.

13. S.Watanabe, T.Araki and H.Miyaji, Proc. ICSTIS, Suppl. Trans.ISIJ,11(1971), 1020.

14. A.J.Bogers and W.G.Burgers, Acta Metall., 12(1964), 255.

15. G.H.Olsen and W.A.Jesser, Acta Metall., 19(1971), 1299.

16. S.R.Goodman and H.Hu,TMS AIME.,230(1964), 1413.

17. H. Inagaki, Trans. ISIJ,17(1977), 166.

18. R.K. Ray, Ph. Chapellier and J.J. Jonas, Textures and Microstr.,12(1990), 141 . 